\title{
El impresionismo en los pintores salvadoreños de inicios del siglo XX en El Salvador
}

\author{
DOI: http://dx.doi.org/10.5377/koot.v0i9.5912 \\ URI: http://hdl.handle.net/11298/442
}

\author{
Leonardo Regalado \\ Museógrafo \\ Universidad Tecnológica de El Salvador \\ leonardo.regalado@gmail.com
}

\section{Resumen}

El Impresionismo, movimiento artístico nacido en la séptima década del siglo XIX, influyó de alguna manera en las primeras generaciones de pintores salvadoreños a principios del siglo XX. Estos pintores nacionales estudiaron con becas proporcionadas por el gobierno salvadoreño en países como Francia, España, Italia y México, que ya habían visto el desarrollo del movimiento impresionista y se encontraban viviendo las consecuencias de la desintegración de la forma en las artes plásticas en el ámbito cultural. Al concluir sus estudios estos pintores salvadoreños regresan al país con un estilo traído de la Europa de finales del siglo XIX y principios del XX a comenzar sus carreras profesionales produciendo una interesante obra plástica que en su iconografía se unen distintas tradiciones culturales resueltas con una técnica pictórica que irá evolucionando con el tiempo y que gracias al esfuerzo de estudiosos en el campo de la historia de las artes no ha caído en el olvido sino que se ha puesto en mesa de discusión periódicamente.

Palabras claves: Pinturas salvadoreñas - Siglo XX., impresionismo (Arte), pintores, Arte.

\begin{abstract}
The impresionism was an artistic movement from the 19th century seventh decade, had some influence on the very first generation of salvadoran painters in the beginnig of the 20th century. These national artists had studied with full salvadoran government help in european and north american countries like France, Spain, Italy and México, that had seen the impresionism growing and were living the consequences of this artistic movement on the cultural environment. On the conclusión of their artístical studies the salvadorean painters came back to their country to begin their profesional carer and breathing up an
\end{abstract}


interesting visual production in wich an unic iconography expresses the half blood cultural heritage with a pictorical impresionist pictorical technic borned in Europe that will be evoluting on time and with the effort of scholars never has been forgotten and however it has been periodically on the place for discussion. of philosophy. On one hand, Zubiri philosophy is rigorously metaphysical or philosophy of reality. On the other hand, Simmel chose to emphasize the ideas that show us some clues about the importance of philosophy. This article has been designed as a topic open to discussion and dissension.

Keywords: Salvadoran paintings - 20th century, Impressionism (Art), Artist/ painter, Art

\section{Antecedentes}

\section{Las primeras academias de pintura y los primeros artistas en EI Salvador.}

El Salvador inició su vida como república desde 1821, año en que se independizó, junto a las demás provincias vecinas, ahora países centroamericanos, de la corona española. Aun así la nueva república sufrió una anexión a México, de 1822 a 1823 (Melgar Brizuela, 2012) y un largo y tortuoso camino al pertenecer a la Federación de Estados Centroamericanos, proceso de encuentros y desencuentros de las clases dominantes en su lucha por el poder en las recién independizadas provincias centroamericanas (Ibídem, 2012).

Debido a este largo período de inestabilidad del poder durante la primera mitad del siglo XIX, muchas instituciones vitales para el buen funcionamiento del Estado salvadoreño tardaron demasiado enaparecer, bancos, casas de estudio superior, instituciones militares y centros de enseñanza del arte no serán realidad sino hasta finales de este siglo, lo que retardó el surgimiento de artistas plásticos con visiones más modernas ya que la llegada del siglo XX sorprendió a algunos de ellos reproduciendo todavía estampas religiosas por encargo de cofradías y patrocinadores religiosos, cuando ya en Europa los movimientos artísticos como el impresionismo, el simbolismo, el historicismo entre otros preconizaban una nueva puesta en valor de la expresión artística y se encaminaban a lo que los críticos más progresistas llamaron "avant garde”, término francés que significa "vanguardia".

Entre 1860 y 1880 el cultivo del café cobró auge económico y el Estado se moderniza creando instituciones especializadas para la difusión de la cultura, estas fueron el Museo Nacional, la Imprenta Nacional y la Biblioteca Nacional (Walter, 2014). No se pensó en una institución especializada en la enseñanza artística plástica hasta 1865 cuando se creó la Academia de Bellas Artes del Salvador durante la presidencia de Francisco Dueñas e inserta en el Colegio Nacional siendo su primer maestro el guatemalteco Manuel José Letona y los profesores fueron Charles Emile Dorat, de nacionalidad francesa y Auguste Feusier, suizo. Este proyecto durará hasta 1869, debido a la renuncia de 
Letona, poniendo fin a la primera Academia de Bellas Artes en El Salvador. Un segundo proyecto inició en 1866 bajo la dirección del salvadoreño Juan Lacayo, pero este murió en 1868 , pasando a ser dirigida por Charles Dorat quien amplió y modernizó sus instalaciones extendiendo la academia hacia el área de música, siendo Alfredo Lowenthal el primer profesor de música (Palomo, 2017) esta academia permanece hasta finales de la década de 1890, no volviéndose a tener noticia de su existencia en el país después de esa fecha (Ibídem, 2017).

Durante todo este período inestable de orden político y social los gobiernos de turno tuvieron la intención de enviar a los primeros pintores nacionales a especializarse en las academias europeas, tal es el caso de Wenceslao Cisneros (Cea, 1984; Palomo 2007; Cristiani y Palomo, 2009, Palomo, 2017), y Juan Lacayo entre otros (Ibídem, 2017).

Al igual que algunos artistas plásticos latinoamericanos, nuestros artistas no pusieron atención a los nuevos movimientos de vanguardia de ese entonces, sino al contrario, se apegaron a la tradición figurativa europea, cuyas raíces proceden desde el renacimiento, ya que por encargo mismo del gobierno salvadoreño, así como por formación artística debían de realizar copias de obras de los grandes pintores renacentistas y períodos históricos posteriores. La etapa de experimentación con las técnicas aprendidas así como de temáticas más propias o personales vendrá después (Cea, 1984; Erquicia, 2012).

\section{A principios del siglo $\mathrm{XX}$}

Ya a principios de 1900 el Estado salvadoreño promovió un discurso de identidad ciudadana basado en "un nuevo modelo de ciudadano civilizado, moderno, mestizo, étnico y culturalmente homogéneo" (Erquicia, 2012) por medio de la construcción de monumentos arquitectónicos y plazas públicas de que mostraran a los héroes de la independencia y los momentos cumbres de la gestación de la República de El Salvador, así como presentar signos o símbolos que construyan el concepto de una nación, busca construir un discurso artístico en el cual se muestre la belleza del paisaje natural y humano salvadoreño que presentara al mundo un país moderno y civilizado con interés en su historia, en el progreso y la cultura por medio de la creación de instituciones de enseñanza artística, de esta manera se convierte en el principal patrocinador de muchos pintores salvadoreños pagándoles estudios en academias europeas y norteamericanas.

Desde ahí muchos de ellos aprendieron nuevas técnicas pictóricas provenientes de movimientos artísticos relativamente recientes en la Europa decimonónica, como el impresionismo, cuyos últimos ecos serán recogidos por pintores como Carlos Alberto Imery, Miguel Ortíz Villacorta, Pedro Ángel Espinoza, y hasta José Mejía Vides y César Sermeño, también en el caso de los pintores formados en México, como Mejía Vides y Camilo Minero, con tendencia a la pintura de 
temática social y con técnicas pictóricas derivadas del movimiento muralista del México de revolucionario de inicios de la segunda década del siglo XX.

\section{El impresionismo del siglo XIX como una referencia del siglo $\mathrm{XX}$}

El impresionismo fue un movimiento pictórico nacido en 1874 en Francia, cuyo principal tema en las obras plásticas fue la relación de los objetos y la luz, la atmósfera que los envuelve y la gama cromática demarcada por una aplicación libre de colores contrastantes. Tuvo como principales exponentes a Edouard Manet, Edgar Degas, Pierre Auguste Renoir, Claude Monet, Paul Cezanne, Vincent Van Gogh, Marie Casatt, Paul Signac, Georges Seurat y otros (Courthion, 1977).

Este movimiento es uno de los primeros en romper las tradiciones pictóricas que venían dadas desde el Renacimiento italiano desde el siglo XVI en los cuales la línea y la iluminación de los objetos en el cuadro estaban concebidas por los conocimientos del pintor, de acuerdo a su cultura académica, lo contrario de los pintores impresionistas, cuyos cuadros son estudios del natural de acuerdo a sus experiencias, a sus vivencias en el entorno natural, esto llevó al pintor a salirse del estudio, en donde tradicionalmente pasaba largas horas pintando de acuerdo a los antiguos tratados de pintura, y experimentar la luz interactuando con su entorno directamente por medio del plen air (Ibídem, 1977), de ahí que cada cuadro impresionista sea una experiencia del artista expresada en términos de color por medio de un tratamiento en el cual el dibujo es prácticamente inexistente, consistiendo en una serie de pinceladas sueltas que al observarse a la distancia convergen y estructuran elementos visuales, dando la "impresión" de ser un objeto.

Este fue uno de los movimientos que más influencias ha tenido en Los pintores latinoamericanos de principios de siglo, basta citar a Armándo Reverón, Alberto Acuña, Próspero Martínez entre muchos otros (Bayón, 1991) y los pintores salvadoreños no serían la excepción.

Algunos de ellos comenzaron su andadura artística en talleres de escultura religiosa como es el caso de Carlos Imery y Camilo Minero, quienes dieron sus primeros pasos en el taller de Marcelino Carballo, pintor autodidacta que pintaba copias de estampas religiosas. Inquietos como fueron, siempre buscaron estudiar en el extranjero, aprendieron nuevas técnicas pero solamente unos pocos escribieron sobre su experiencia en la pintura escribiendo también poco.

A diferencia de los artistas plásticos del resto de países latinoamericanos, cuyo aprendizaje también había sido en academias de Europa y en algunos casos crecieron bajo el influjo de las vanguardias artísticas de principios de siglo XX (Bayón, 1991), los pintores salvadoreños no fueron muy dados a las corrientes de vanguardia, tampoco teorizaron mucho sobre las corrientes pictóricas bajo las cuales organizaron su propuesta, al parecer gustaron más de aquello que se 


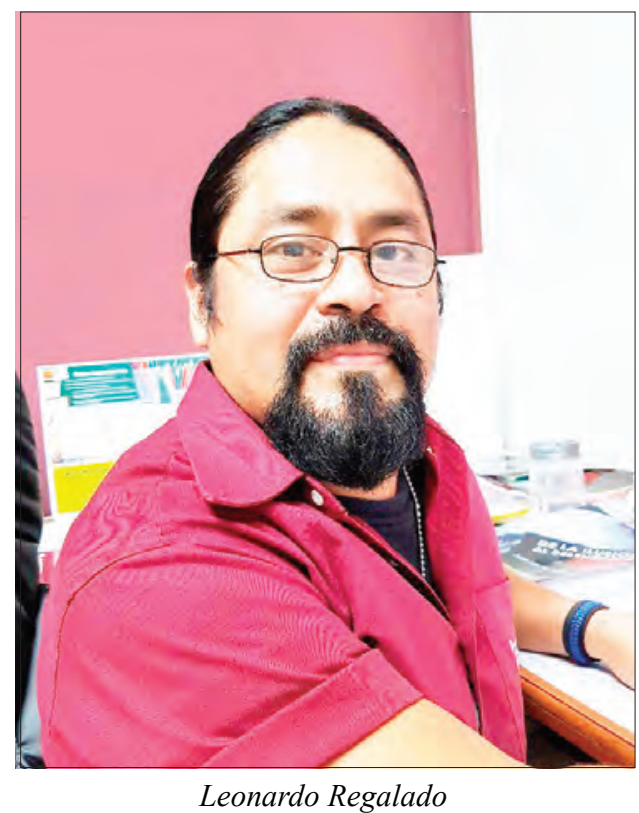

Con estudios de arqueología, artes y museología

podía apreciar más luego a simple vista, y darle continuidad a un figurativismo más del gusto de la población de su país de origen.

Lo más urgente que les reclamó la sociedad fue el de enseñar el oficio de pintor, y quizá haya sido la forma más rápida de ganarse la vida, ya que en ese momento no existe un mercado artístico plástico en el cual el artista comercialice su obra, ni tampoco se contaba con no hay locales apropiados para exhibiciones de pintura como galerías, pinacotecas o algo parecido, apenas se contaban unos cuantos espacios estatales como el Museo Nacional, la Universidad de El Salvador y algunos locales comerciales como la Marmolería Ferracutti, debido al poco interés del Estado en la producción plástica, seguramente porque las clases sociales de aquel entonces concebían a la pintura como un oficio de producciones meramente decorativas, en cambió invirtió mucho más en la producción escultórica, ya que esta le servía mucho más para difundir los valores culturales oficialistas en plazas y otros espacios públicos, débilmente se interesó en crear academias o escuelas y encomendar su dirección a estos pintores a los cuales les había posibilitado su formación técnica en el extranjero (Ibídem, 1984, Walter, 2014, Palomo, 2017).

Es así como algunos de ellos, en especial Carlos Alberto Imery, se dedican a la enseñanza del dibujo y la pintura en lo que el gobierno de turno crearía en 1913 como la Escuela Nacional de Artes Gráficas, institución estatal que fungiría más bien como una escuela técnica, con materias de ciencias aplicadas cercanas a las artes gráficas (química aplicada a la impresión, mecánica, foto grabado, 
litografía tipografía entre otras) que como una escuela de bellas artes, pero que aun así, daría como fruto el inicio de las carreras profesionales de pintores como José Mejía Vides, Camilo Minero, Miguel Ángel Salinas y Carlos Cañas entre otros, pintores estos que a su vez marcharon a México y Europa para terminar de formarse (Ibídem, 1984).

En cuanto a la obra de Imery, de marcada influencia impresionista, su paleta se basa en colores pastel (violeta, celeste, rosa) con algunos contrastes, así como su pincelada suelta muy del estilo impresionista, tanto que en sus principios su obra se confunde con la de cualquier otro pintor europeo impresionista (Cea, 1984), no existe en este momento ningún ícono que referencie el ámbito cultural salvadoreño, se observan en sus cuadros personas con apariencia caucásica propios de Europa occidental, no es sino hasta que el pintor se encuentra de vuelta en el país que su temática comienza a reflejar el mestizaje cultural en cuadros como "Campesinos", "Paisaje", "La ceiba en el cementerio" "El muchacho de la máscara", cuadros pintados entre 1912 y 1920, con un tratamiento academicista europeo pero con elementos identitarios ya autóctonos como rostros indígenas, geográficos como la campiña salvadoreña u objetos de origen étnico como la máscara propia de la danza de Los Historiantes que aparece en uno de sus cuadros (Cea, 1984).

Junto a Imery se sitúa otro pintor que también recibió su formación académica en Italia, es Miguel Ortíz Villacorta. En sus pinturas puede apreciarse la preocupación por la luz y la atmósfera, así como la preferencia por la campiña salvadoreña y se reflejan en cuadros como "Valle del Jiboa", composición en la que destaca el volcán Chinchontepec, en donde se ve un paisaje que presenta una acusada intervención del ser humano por medio la agricultura, actividad que ha configurado su cultura durante más de 20 siglos, así mismo el volcán es un referente identitario para los salvadoreños. Resuelto con una técnica impresionista en la que destaca la pincelada suelta, así como el uso de una gama cromática en armonías de verdes y amarillos que caracterizan inmediatamente al cuadro.

Ortíz Villacorta tiene otras telas en donde destacan referentes geográficos de los países en los cuales residió tales como el "Volcán de San Salvador" y "Bosque de Chapultepec" de El Salvador y México respectivamente. Pero hay un punto importante que destacar en Villacorta y es su intención de plasmar el paisaje humano en las áreas rurales siempre con una técnica impresionista muy bien asimilada. En estos cuadros pude apreciarse el contraste de la luz y la sombra, la cotidianidad y la sencillez de vida campesina así como un acucioso detallismo de la fisonomía indígena y mestiza, no en balde es uno de los mejores retratistas de la historia del arte salvadoreño así lo demuestran algunos de sus retratos hechos a notables del país que ahora son parte de la Colección Nacional de Artes Visuales del país. 
Es aquí en donde puede verse una búsqueda más apremiante y un estar más en contacto con la clase campesina que rindió una praxis artística más cercana a nuestro país que la que hiciera Imery, lo que le permitió a Villacorta plasmar una realidad nacional que aún hoy se observa en el país con una exactitud casi "etnográfica" como una "descripción densa" al decir del etnólogo Marcel Maus (1967). Ortíz Villacorta también fue director de una efímera academia de dibujo y pintura entre 1929 y 1931 (Cea, 1984).

El caso de Pedro Ángel Espinoza es aún más interesante dado su origen étnico y social. Y aunque estudiado en Europa en Milán, Italia, no tuvo aceptación en los círculos intelectuales del país por su extracción social popular y su condición cultural de indígena (Cea, 1984), pero esto no detiene al pintor, ya que origina una serie de cuadros cuya temática central es precisamente el pueblo indígena en su realidad cotidiana, pintado con un fuerte colorido y retratado con pinceladas que reflejan el carácter bravo y austero de estos pueblos, tal es el aspecto que muestran en cuadros como "Mercado" y "El gallero".

Espinoza respira el ambiente popular en sus cuadros, en cierta forma son cuadros con un influjo indigenista resueltos técnicamente con gruesos impastes netamente impresionistas y una composición muy esquemática, es decir, de fácil lectura dada la economía un tanto austera de estas imágenes. Espinoza respira también el agitado ambiente social en el que se desenvuelve su clase social de origen, sabe cuáles son las aspiraciones de este grupo cultural invisibilizado por los círculos de poder por lo que crea una escena socialmente utópica, digna de un muralista mexicano, en su cuadro titulado "La primera reforma agraria en 1932", irónica y trágicamente a principios de esta década miles de indígenas son masacrados cobardemente por las fuerzas militares del Gral. Maximiliano Hernández Martínez en Izalco, dejando de lado toda oportunidad de expresiones utópicas.

José Mejía Vides fue un pintor que aunque formado en México bajo la escuela muralista, siempre pintó algunos de sus cuadros con técnicas que recuerdan a los impresionistas Gauguin y Seurat. Mejía Vides despreció la ciudad y tomó una actitud parecida a la de Gauguin, prefirió aislarse en una comunidad y desde ahí transmitirnos ese candor ingenuo de los nativos retratados con un colorido muy parecido al del maestro francés, además de resolver algunos de sus cuadros con una técnica puntillista propia de Seurat e imitada también por el colombiano Alberto Acuña, coetáneo de Mejía Vides, y que más tarde utlizará el ceramista César Sermeño en su cerámica y en sus acuarelas.

El impresionismo ejerció bastante influencia en pintores de generaciones posteriores entre los que podemos citar a Pedro Acosta García, el ceramista César Sermeño, Raúl Elas Reyes en sus primeros tiempos, entre otros. Seguramente porque ya era movimiento histórico visto en en las escuelas donde 
se formaron, al decir del pintor Armando Solís en su libro "Oficio de Pintor. Estética Latinoamericana":

"Con el compañero Antonio Rosales, polemizábamos, discutiendo por este arte. No obstante que en nuestro país estaba de moda el arte abstracto, no asimilábamos nada de esta corriente. Es posible que influyera el tipo de enseñanza que recibiamos que era de carácter figurativo académico. Pero era evidente que nuestra inquietud, nuestros dioses de la pintura eran Manet, Monet, Degas, Pizzarro, Gauguin, Van Gogh, Toulousse - Lautrec, etc. Nos recreábamos con sus principios y estudios sobre la luz, en verdad, no sabiamos el verdadero motivo y causa de ese movimiento. Para nosotros era más que todo romántico salir a pintar al aire libre nuestros paisajes. Dejó de serlo, cuando viviendo mi propia realidad, expreiencias no tan gratas, mucho menos románticas, descubri mi verdadera posición del arte. Comencé a viajar observando museos famosos, para completar mi preparación visual." (Solis, 1985).

Con esta cita de un pintor que no pinta como un impresionista, puede verse claramente el porqué del apego figurativista de la muchos de los pintores "mayores", lo romántico y académico pesó en cierto modo más que lo experimental, el ya acostumbrado figurativismo por su larga tradición siguió influyendo a más pintores aún a mitad del siglo XX, cuando ya la academia de Valero Lecha comienza a lanzar generaciones de pintores más dados a la experimentación, menos prejuiciados contra los nuevos movimientos artísticos europeos y estadounidenses iniciando así una nueva etapa en la producción de las artes visuales salvadoreñas.

\section{Conclusiones}

Por razones socio culturales el aparecimiento tardío de instituciones especializadas en la enseñanza artística, lo que equivale a una prolongada ausencia de éstas, retrasó considerablemente el aparecimiento de artistas con visión más moderna en el campo de la producción plástica salvadoreña, lo que incidió en un notable atraso que el país tuvo en el desarrollo de las artes visuales, así como la participación de éste en los movimientos artísticos de aquel entonces.

El Estado salvadoreño patrocinó económicamente a los primeros pintores salvadoreños que estudiaron en academias europeas a finales del siglo XIX y principios del XX y que absorbieron las influencias del impresionismo, Carlos Alberto Imery, Miguel Ortíz Villacorta y Pedro Ángel Espinoza son quienes comenzaron a buscar en el paisaje natural y humano una propuesta más moderna y menos religiosa y romántica que la pintura de siglo XIX. Se puede decir que estos tres primeros son los iniciadores de la pintura moderna en el 
país ya que comenzaron de una forma incipiente a desarrollar una obra pictórica más relacionada con elementos identitarios salvadoreños étnicos, humanos y geográficos que son los componentes visuales de su obra plástica y de la que las generaciones posteriores tomarán referencia.

La pintura de estos artistas va a caracterizarse por el uso de pinceladas sueltas o fragmentarias, empastes gruesos, contrastes de color bastante marcados sobre todo en la obra de Ortíz Villacorta y Espinoza, preocupación por la naturaleza de la luz sobre todo en Imery y Ortiz, mientras que Espinoza es un fuerte colorista más centrado en el contraste y en la empatía humana de sus retratos de indígenas, representantes de la clase a la que él perteneció.

Surge una pregunta: ¿A qué se debió que nuestros artistas no siguieran las tendencias más recientes en el continente europeo, ya en boga por aquellos tiempos?, ¿pesó más en ellos la tradición figurativa del devenir artístico de nuestro país? sin duda la respuesta a estas preguntas estriba en la marcada tradición pictórica figurativa que se impuso en largo período colonial y que debido a la falta de una institución de enseñanza artística plástica que fuese abierta a nuevos cánones, así como de una sociedad en eterno conflicto de intereses políticos y económicos, de marcado carácter conservador, su provincianismo, no permitió que esa modernidad artística arraigara desde finales del siglo XIX, fenómeno que no es propio solamente del país sino del orbe latinoamericano (Bayón, 1991).

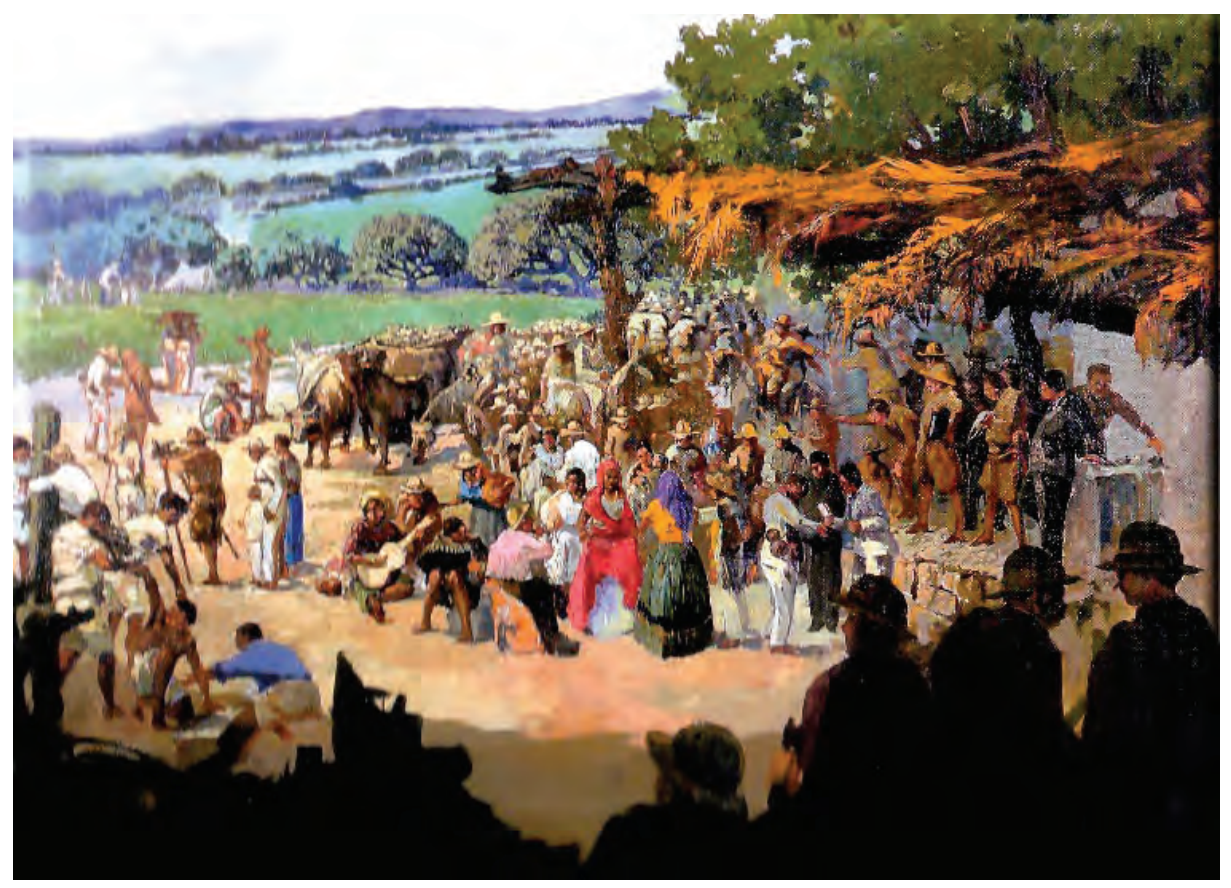

Pedro Ángel Espinoza (1899 - 1939) "Primera reforma agraria”, 1935. Óleo sobre tela. Colección nacional. 

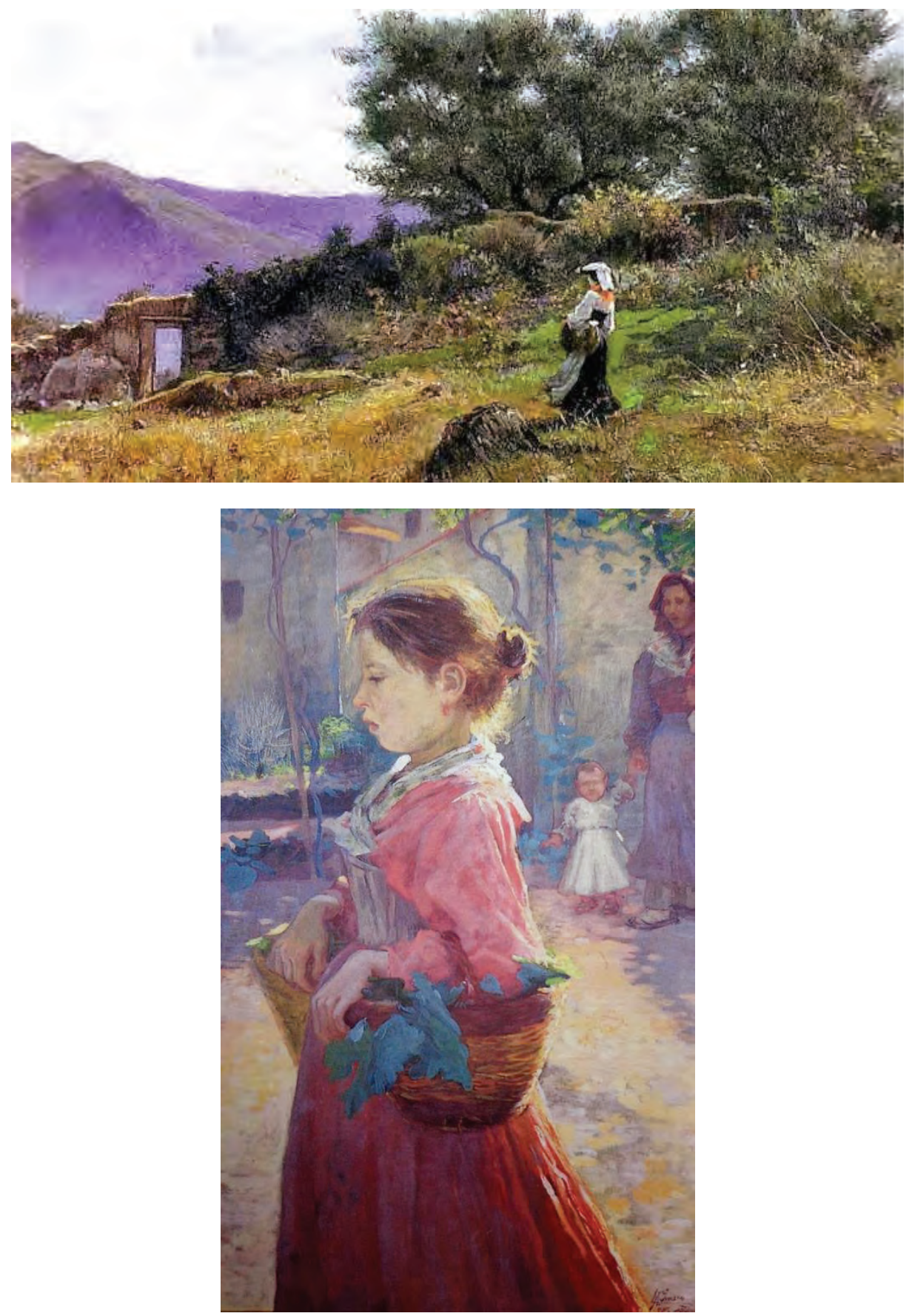

Carlos Alberto Imery (1879 - 1949). Arriba "Campesina italiana” (1904) Óleo sobre tela. Cortesía, Museo Forma. Abajo "Plazoleta de las hierbas" S/f. Óleo sobre tela. Colección particular. 

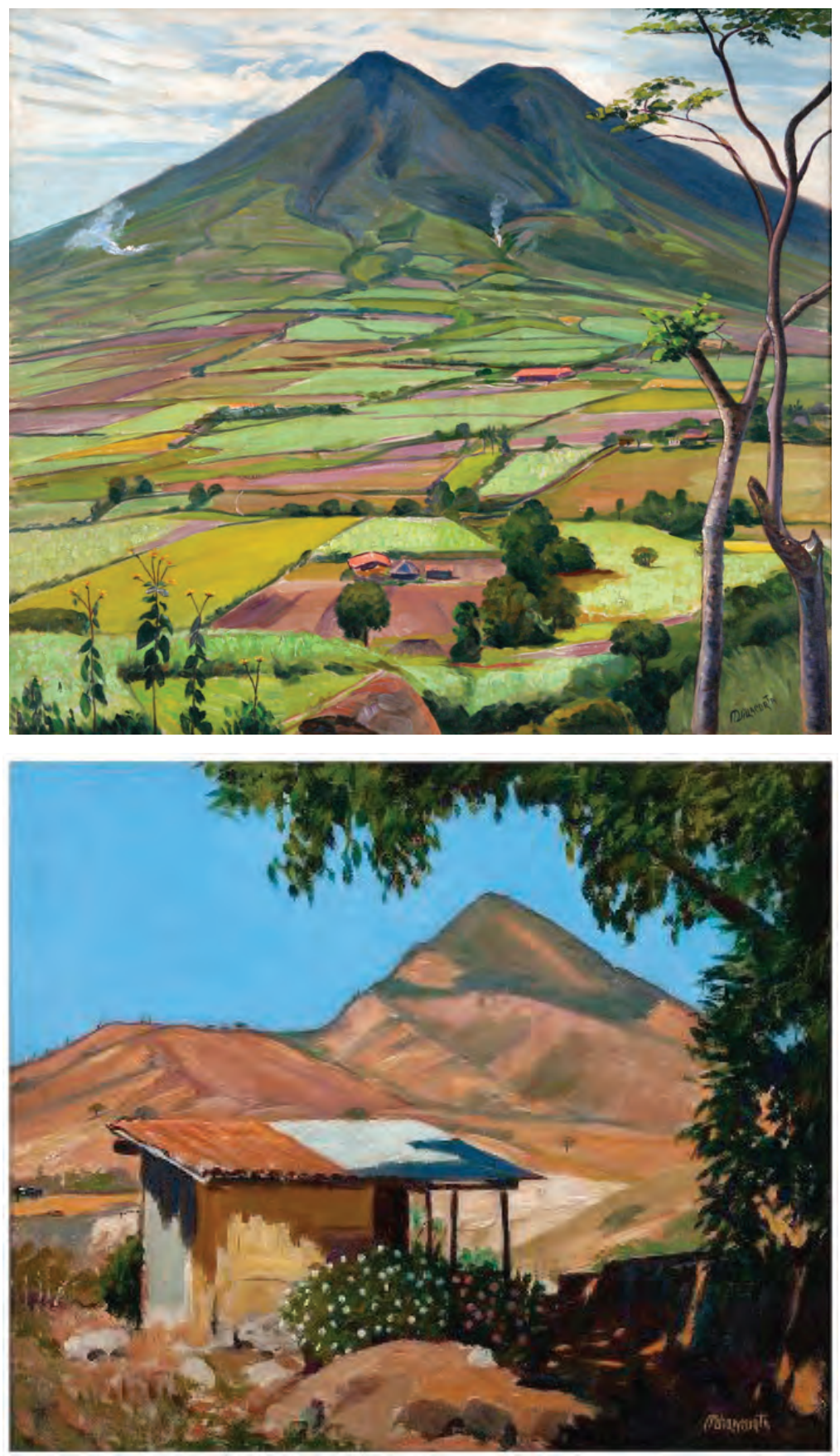

Miguel Ortiz Villacorta (1887-1963) Arriba "Valle de Jiboa" (1925) Óleo sobre tela. Colección Nacional. Abajo "Volcán de San Salvador" (1950) Óleo sobre tela. Colección Nacional. 

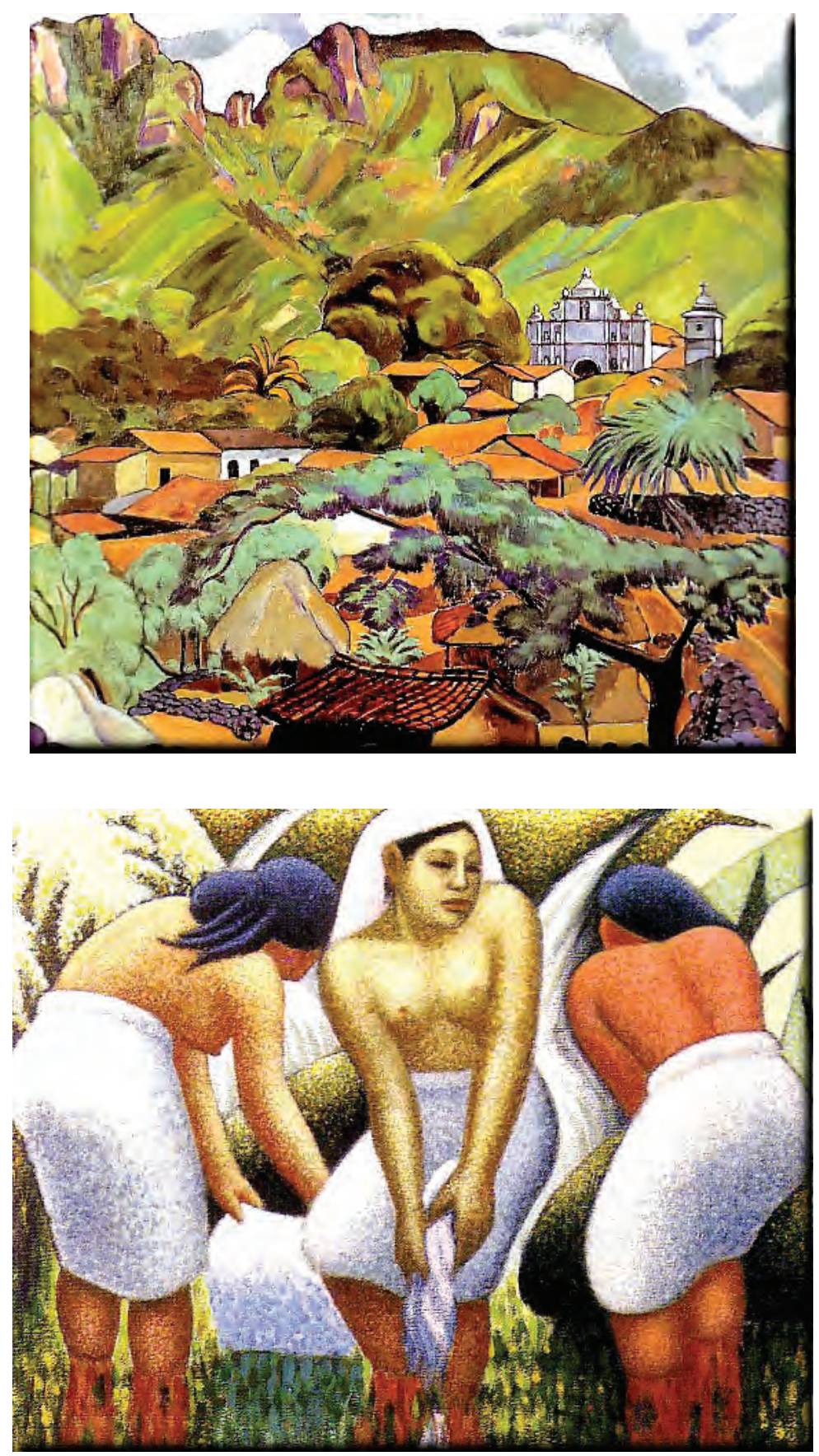

José Mejía Vides (1903 - 1993) Arriba: "Panchimalco" (1935). Óleo sobre tela. Abajo "Lavanderas" S/f. Óleo sobre tela. 


\section{Referentes bibliográficos}

Bayón, D. (1991). Aventura plástica de Hispanoamérica. México, D. F.: Fondo de Cultura Económica.

Cea, R. (1984). De la pintura en El Salvador. San Salvador: Publicaciones e impresos.

Courthion, P. (1977). Impressionism. New York: Harry N. Abrams, Inc.

Cristiani, C., \& Palomo, I. (2009). Museo del Arte de El Salvador, artista del mes 2003-2009. San Salvador: Museo de Arte de El Salvador, MARTE.

Erquicia Cruz, J. H. (2012). El elemento estético indígena y/o prehispánico en el patrimonio artístico salvadoreño como expresión de la identidad nacional. Revista de Museología Kóot. 2(3), 66-78.

López, M. E. (1974). Interpretación social del arte. San Salvador: Dirección de publicaciones e impresos.

Melgar Brizuela, J. (2012). Estudio histórico: proceso de Independencia, 1811823. San Salvador: Universidad Tecnológica de El Salvador.

Museo de Arte de El Salvador, MARTE. (2007). Revisiones: encuentros con el arte visual en El Salvador. (Tomo 1). San Salvador: Museo de Arte de El Salvador, MARTE.

Selva, J. (1957). La pintura alemana en el siglo XIX. Barcelona: Ramón Sopena.

Walter, K. (2014). Las políticas culturales del estado salvadoreño, 1900-2012. San Salvador: ACCESARTE. 